\title{
TWEE KOPEREN OORKONDEN VAN BALITUNG IN HET KOLONIAAL INSTITUUT TE AMSTERDAM
}

DOOR

F. H. VAN NAERSSEN.

In het voorjaar van 1934 werd mij door Prof. J. C. van Eerde, directeur van de afdeeling Volkenkunde van het Koloniaal Instituut te Amsterdam verzocht een transcriptie, vertaling en bespreking te geven van een tweetal koperen platen, die aan het museum zijn geschonken door den Heer F. G. Doorenbosch, ,die zegt dat zij afkomstig zijn van Midden-Java (vermoedelijk Pekalongan, of Tegal); nadere gegevens zijn daaromtrent niet bekend" ${ }^{1}$ ).

Transcriptie, vertaling en bespreking zijn te vinden in de „Aanwinsten" ${ }^{2}$ ) van 1934. Aangezien uit den aard van deze publicatie (een catalogus van hoofdzakelijk enthnographische zaken) de kans groot is, dat zij niet licht zal worden geraadpleegd door den archeoloog of historicus en vooral mede doordat de transcriptie opgenomen in bovengenoemde publicatie uit hoofde van typografische bezwaren niet geheel tot haar recht is gekomen ${ }^{3}$ ), heb ik het niet ondienstig geacht hier nogmaals een transcriptie van deze twee koperen platen te geven.

Bij het transcribeeren heb ik mij bediend van de volgende teekens:

$[\ldots]=$ weggevallen akṣara's door mij naar analogie van parallelle plaatsen ingelascht.

$-=$ een akșara weggevallen.

$\ldots \ldots .=$ meer dan een akṣara weggevallen.

Twijfelachtige lezingen zijn cursief gedrukt.

\section{OORKONDE I.}

A. 1. swasti çakawarṣātīta 829 baiçākhamāsa tithi caturthi krṣṇapakṣa mawulu wagai somawāra uttarāpāḍanakṣatra çuklayo

2. ga tatkāla anugraha çrī mahārāja raka i watu kura dyạ̣

1) Volgens een particulier schrijven van Prof. van Eerde aan mij.

2) „Aanwinsten op ethnografisch en anthropologisch gebied van de afdeeling Volkenkunde van het Koloniaal Instituut over 1934", pag. 135-144.

3) De drukkerij waar de „Aanwinsten” gedrukt worden bezit geen lettertypen met een punt eronder, zoodat in de transcriptie $n, t, d$, s, etc. staat waar respectievelijk n, ț, d̦, ș, etc. behoorde gelezen te worden. 
balitung çrī dharmmodaya mahāsambu tumurun i rakryān mapatih i [hi]

3. no pu dakṣottama bāhubajra pratipakșakșaya kumon samgat lamwa pu layang anak wanua i patapān tutugan ning tạ̣̣a

4. sumusuka i kanang wanua i sangsang watak lamwa gawai ku 2 drawya haji nya mas su 7 mas kawahutān su 2 suwur hinawu-ha

5. wu sambandhā nya kinon sumusuka i kanang wanua wuara kuṭi i hujung galuh watạk lamwa ya ta pinulị̣ samgat lamwa pinahayu-nira jina

6. yyakan nira wihāra ya sambandhā nya $r$ inanugrahān kinon sumusuka i kanang wanua i sangsang simā punpunnana -ni kanang wihāra gawai

7. nira ${ }^{\circ}$ kunang parṇnaḥha-nya $n$ sīmā tan katamāna de sang mānak pangkur tatun (lees: tawan) tirip ${ }^{\circ}$ muang soara ning mangilala drabya haji ${ }^{\circ}$ kring paḍa

8. m pamanikan ${ }^{\circ}$ maṇiga lwa malañjang manghuri makalangkang tapa haji air haji tuha goçali tuha dagang tuhā nambi tuhān hañjama

9. $\mathrm{n}$ uṇ̦ahagi manimpiki paṇ̦ai $\mathrm{wsi}^{\circ}$ walyan paranakan widu mangidung tuha paḍahi warahan sambal sumbul watak i dalam si

10. nggah pamṛmi hulun haji ityaiwamādi tan tumamā i ri kanang wanua ${ }^{\circ}$ parṇnaḥ ni parmmasa-nya tumamā i bhațāra i wihāra i hujung galuh

11. deya-nya mawaih mannangahanang tang (of: mannanga hana ing?) parmasan ${ }^{\circ}$ ing kataṇạan samangkana sukaduhkha nya mayang tan mawuah ḍaṇ̣a kuṇ̣a (lees: kuḍaṇ̣a) bhaṇ̣ihālādi tuma

12. mā i bhațāra atạh i kana ājña haji ${ }^{\circ}$ kinonnakan i kanang masamwyawahāra hana ng kāna hīnghingana kwaihha-nya paṇuai mas $^{\circ}$ paṇuai si $^{\circ}$ ta

13. mbaga $^{\circ}$ gang $[\zeta] \mathrm{a}^{\circ}$ tlung ububan ${ }^{\circ}$ ing sa sima ${ }^{\circ}$ macadar 4 mangarah lumpang 3 mangulang tlung tuhān ing sa sīma ${ }^{\circ}$ kbo anya 20 ing sa tuhān ${ }^{\circ}$ sapi

14. $-0 \ldots \ldots$ (elders b.v. O.J. O. XXXIX. 22: 40 wḍus) 80 aṇdah wantayan 1 parahu - bhațāra 1 masunghara 3 tan patuṇ̂āna magulungan tlung pasang samangkana tan

B. 1. knān[a i para]masan yāpuan pinikul daganga-nya kadyanggāning mabasana masa[yang] makacapuri kapas wungkuḍu tāmbra gangsa sobuban i sa tuhā 
2. $\mathrm{n}^{\circ}$ garam paḍak lnga gula ${ }^{\circ}$ sa prakāra ning dual pinikul kalima bantal i sa tuhān pikul-pikulana-nya ${ }^{\circ}$ tlung tuhān ing sa sī

3. ma i kanang samangkana tan knāna de sang mangilala drabya haji ${ }^{\circ}$ yāpuan lwị kwaị nya sangkā i ni kānang panghīnghīng i ri ya knāna i kana saka lwị

4. nya de sang mangilala sodhāra haji ${ }^{\circ}$ kunang i kanang mañambul $^{\circ}$ mañawring mangapus ${ }^{\circ}$ manglākha daṇḍaha nira mamungus mangubar ${ }^{\circ}$ manahab manuk

5. mamisaṇụng manganammanam ${ }^{\circ}$ mamukat wungkuḍu manarub mangdyūn manggula manghap $\bar{u}^{\circ}$ ityaiwamādi kapua ya tribhāgān sa dūman ${ }^{\circ}$ umarā

6. i bhațāra sa dūman umarā i sang mangilala drabya haji sa dūman umarā i sang makmit $\operatorname{simma}^{\circ}$ mangkana ājña haji panghinghing i rihāh mapamwyawahā

7. ra (elders b.v. O.J. O. $X X X$ voorz. 28: i rikanang sambyawahāra) hana ng kāna mangasiakan samgat lamwa pasambạ i çrī mahārāja w đ̣ihan piliḥ magöng yu 1 w ḍihan jagā yu 1 mas su 1 māra rakryān mapati[h]

8. i hino inangsian w ḍhan kalyāga yu 1 mas su dhawa kryān (beter: mas su 1 rakryān) i halu pu wīrawikrama inangsian wdịhan talyāga yu 1 mas su 1 rakryā

9. n wka pu kutak inasěan w ḍihan kalyāga yu 1 mas su 1 rakryān sirikān pu wariga inangsian w ḍihan kalyāga yu 1 mas su 1 samga

10. $\mathrm{t}$ tiruan pu çiwastra inasian w ḍihan kalāy ${ }^{4}$ ) yu 1 mas su 1 raka i pagar wsi pu yayak inangsěan w ḍihan yu 1 mas mā 8 samgat

11. mamrati pu uttara irasisan wḍahan yu 1 mas mā 8 samgat wadhihati pu dhapit makudur pu samwṛda pangkur pu rañjan tawān pu parjaluan kapu

12. a wineh pasak-pasak w ḍihan yu 1 mas mā 8 sawang sowang samgat juru i tadangayan samgat walimwangan pu çima inasisan wdiha

13. n kalyāga yu 1 mas mā 8 tuhān i wawihati sang winungkuzwan pu adhikara wīnaih wḍihan yu 1 mā 5 i makudur sang miramira $^{\circ}$ winaih w diha

14. n yu 1 mas mā 5 satangya $i$ walimwangan tanuwuk daangi kapua winaih wḍhan yu 1 mas ma 3 zeruhuta knam marzola wahuta -

4) N.B. Van hier af, tot het einde is het schrift zeer slordig; men verbetere naar analogie van parallelle plaatsen in andere oorkonden. 
15. wḍinua hujung masib dhan kapua winaih wdihan yu 1 has mā 2 soang sowang sang wadya dadis anak wanua i kilipan winaih wḍihan yu ..... cetera desunt.

\section{OORKONDE II.}

A. 1. ..... pkan si tuwuku parujar si sidra malawai si basanta winaih w ̣̣ihan yu 1 sowang rāma maratā kaki kuṇ̣̣u muang si wlya winaiḥ wḍihan yu 1 soang rāma māgman i wuru tlu tumpang

2. si mandon rāma ni rasuk parujar si ḍaheng rama ni kaṇți winailı wdihan yu 1 soang gusti i tumpang sang ganggang rama ni baladì parujar sang laṇụ rama ni bhanda winaị w ḍihan

3. yu 1 soang gusti ing wukajana si butě rama ni bantin parujar si gamana rama ni krama winaih w ̣̣ihan yu 1 soang rakryān añjatan pu sāgara samgat tunggu pu ...... winaih w ḍiha

4. n yu 1 soang rāma tpi siring gusti i dalinan si kekeh, rama ni $d w \overline{1}^{\circ}$ muang si wlat $^{\circ}$ parujar si ganal rama ni sawasti muang si hala rama ni ngwině winaị w ̣̦ihan yu 1 soang

5. i mahariman kalang si knoḥ rama ni santěl gusti si puñjö rama ni $\operatorname{padmi}^{\circ}$ muang si çarah rama ni gadik ${ }^{\circ}$ parujar si deçi rama ni rakși muang si çarana rāma i kisik wi

6. naị w dihan yu 1 soang $^{\circ}$ i huwus ning mawaih mas pasakpasak muang wḍihan pinarṇah saji sang makudur manguyut wdihan sang hyang kulumpang yu 4 batu-batu

7. mas mā 4 w ḍihan yu 1 sang hyang brahmā yu 1 mas mā 1 pangisi tamwakur pinakasawur-sawur sang manguyut wěas kukusan 1 wsi ikat 1 mas mā 4 pa

8. da 1 wṣi nya ikat 10 mas mã 1 w ḍus 1 hayam lanang hirĕng 1 hantalu ning hayam 4 tanḍas ning kbo 1 kumol 1 pras maanuka 1 skul dinyun 5 tu

9. lung tapa $k$ liman $1^{\circ}$ pasilih geluh yu 1 argha padya indit 5 tamwata prakāra kawah 1 dyun 1 dāng 1 buri 1 pangliwěttan 1 tarai 1 papañjutan

10. 1 saragi cpak 1 gaça prakāra saragi magöng 1 tahas 1 saragi inuman 3 wsi-wsi prakāra wadung 1 patuk-patuk 1 twak 1 tampilan 1 kris 1 lukai 1 kampi

11. t 1 tatah 1 jara 1 gurumbhāgi 1 pamajsa 1 nakhaccheda 1 gulumi 1 siku-siku 1 linggis 4 laṇ̂uk 1 i sampun-i saji sang manguyut pinarṇah mangdiri samgat kalang wu

12. ngkal muang samgat anakbi dyah sucintě muang dyaḥ kina 
dyaḥ waita dyah sawitā ${ }^{\circ}$ mawaih pañcopacāra i sang mamuat ujar ${ }^{\circ}$ tlas sang mamuat ujar winaih pa

13. ñcopacāra maskar sira majnu ${ }^{\circ}$ mapangalih mangḍiri dumunung ing witāna panguyutan malungguh humarĕp kidul humarapakan sang hyang kudur sang wahuta hyang kudur malu

14. ngguh humarĕp waitan ${ }^{\circ}$ samangkana sang patih wahuta malungguh i pungkuran sang wahuta hyang kudur ${ }^{\circ}$ ikanang rāma i wukajana i tumpang i wuru tlu muang

B. 1. rāma tpi siring kabaih malungguh humarẹp lor raiṇanta umunggu (lees: umungguh) waitan ning witāna umarĕm (lees: umarěp) kuluan ${ }^{\circ}$ samāpta palungguh nira kabaị̣ mamangmang sang makudu

2. $\mathrm{r}$ manětěk hayam linaṇḍasakan i sang hyang kulumpang mamantingakan hantalū ring watu sīma ${ }^{\circ}$ matěhĕr manapaṭhai i kana ling nira indah kita sang hyang sa hana

3. nta sang malmaḥ sang mathāni sa kwaị tā hyang ring pūrba dakșina ${ }^{\circ}$ paçcima $^{\circ}$ uttara $^{\circ}$ āgnaiya $^{\circ}$ nairiti ${ }^{\circ}$ bāyabya ${ }^{\circ}$ aiçānya ${ }^{\circ}$ sang hyang ring satya dharmma ${ }^{\circ} \mathrm{kāla}^{\circ} \mathrm{mṛtyu}^{\circ} \mathrm{krodha}^{\circ}$ wiçwa ${ }^{\circ} \mathrm{ka}$

4. $\mathrm{ma}^{\circ}$ wișnu ${ }^{\circ}$ ing $\operatorname{maddhya}^{\circ} \mathrm{i}$ sor $^{\circ} \mathrm{i}$ ruhur $^{\circ}$ tasmāt kabuat karma nikanang wuang anyāya umulah-ulaha i keng sīma samgat kalang wungkal pu layang nguniwaih ya

5. n ruddhā ya tan tamua phala ning dadi kadyanggān ni kanang hayam pgat tan baluy matpung hantalū rĕměk-rĕmuk tan waluy i luīr nya mangkanā i kanang wu

6. ang durācāra yan ulah-ulaha i kaing sīma ${ }^{\circ}$ umarā ya ring alas patukan ning ulā ${ }^{\circ}$ umarā ya ing tgal alapan ni glap ${ }^{\circ}$ tan pahudan ${ }^{\circ}$ umarā ya ring uai willěttan

7. ni tuwiran ${ }^{\circ}$ tětěkěn de ning wuil ${ }^{\circ}$ pingpingtubimwān pañcamahāpātaka pangguha-nya matang-ya kayatnākna ikeng ajña haji panganugraha çrī mahārā

8. ja raka $\mathrm{i}$ watukura $\mathrm{i}$ samgat kalang wungkal pu layang sumusuka i kanang wanua i wukajana i tumpang i wuru tlu sīmā pumpunana (lees: punpunana) ni kanang bihāra i dalinnan gawai nira

9. makaphalā swasthā sang hyang dharma muang prajạ kabaih kahlama-nya hinyūnnakan ton-tonan mamidu sang tangkil hyang sinalu macaritta bhimma kumāra mangigal kīca

10. ka si jaluk macarita rāmāyaṇa mamirus mabañol si mung-muk ${ }^{\circ}$ D1. 95. 
(of: muk-muk ${ }^{\circ}$ ) si galigī mawayang buat thyang macarita bimma ya kumāra matěhěr manghyunnakan sa

11. - ng kapua rāmanta tpi siring kabaị māwuran ${ }^{\circ}$ umilu Damuatoh rakryān muang makarungakan haji sang tṛpan pu mitra $^{\circ}$ muang pu malawang hulěs umi ...... cetera desunt.

\section{AANTEEKENINGEN.}

In oorkonde I komt de naam van den vorst volledig voor: Çrī Mahārāja Raka i Watukura Dyah Balitung Çrī Dharmmodaya Mahāsambu; en van oorkonde II hebben wij dat fragment over waarin deze vorst naar zijn apanage wordt genoemd : Çrī Mahārāja Raka i Watukura, Z. M. Grootkoning, Heer van Schildpadsteen.

Van koning Balitung hebben wij thans, deze twee oorkondefragmenten medegerekend, zeventien inscripties, die direct of indirect van dezen vorst zelf zijn uitgegaan ${ }^{5}$ ). Een groot aantal, vooral wanneer wij deze hoeveelheid vergelijken met het buitengewoon geringe aantal oorkonden uit denzelfden tijd, uitgaande van anderen dan dezen vorst $\left.{ }^{6}\right)$. Hieruit blijkt wel hoe groot Balitung's centrale macht was in tegenstelling met die van zijn voorgangers uit de bekende vorstenreeks op de oorkonde uit de Kedoe uit 829 Çaka $^{7}$ ). Vooral van de eerste vorsten uit die reeks tot aan Rake Garung is eigenlijk niets positiefs bekend ${ }^{8}$ )

Daarentegen hebben wij ettelijke oorkonden met data uit de regeeringsperiode dezer voorgangers van koning Balitung over, uitgevaar-

5) Een opgave van alle tot nu toe gevonden inscripties uitgaande van Balitung is te vinden in Dr. W. F. Stutterheim's artikel: Een vrij overzetveer te Wanagiri, in T. B. G. 74 (1934) blz. 274.

6) Mij zijn slechts bekend het zilveren en gouden plaatje van Pěsindon uit 826 Çaka (Kern. V.G. VII p. 11-15); O. J. O. XXIX uit 833 Çaka; en eventueel de jayapattra-Dieduksman en de oorkonde in O.V. 1922 blz. 85 (cf. O. V. 1928 blz. 64 en T. B. G. 74 blz. 274), hoewel tusschen de laatstgenoemde inscriptie en koning Balitung verband bestaat gelet op de overeenkomende benaming der hoogwaardigheidsbekleeders.

7) Dr. W. F. Stutterheim: Een belangrijke oorkonde uit de Kĕdoe, in T. B. G. 67 (1927) blz. 189 en 210. 1. Rakai Matarām sang ratu Sañjaya, 2. Çrī Mahārādja rakai Panangkaran, 3. - Panunggalan, 4. - Warak, 5. - Garung, 6. -Pikatan, 7. -Kayuwangi, 8. -Watu humalang, 9. -Watu kura.

8) Behalve van de twee eerste vorsten uit die reeks, Sañjaya en Panangkaran bekend uit respectievelijk de oorkonde van Tjanggal (Kern. V. G. VII blz. 115 sqq.) en van Kalasan in T. B. G. 68 (1928) blz. 58 sqq. „Rakarayān i Garung” komt voor in een inscriptie gepubliceerd door Dr. R. Goris in O. V. 1928 blz. 65 
digd nièt door deze machthebbers uit de zooeven genoemde vorstenreeks ${ }^{9}$ ). Vooral het feit dat deze oudste oorkonden opvallend sterk een lokale kleur hebben, waaraan uniformiteit totaal ontbreekt ${ }^{10}$ ), doet ons aan een groote en centrale macht van de oudste mahārāja's van Midden-Java twijfelen en ons afvragen of deze oorkonden niet uitgegeven zijn door machthebbers die geheel onafhankelijk waren van de vorsten, genoemd in de reeks.

Wij stellen ons namelijk voor, dat Java vóór de komst der Hindu's, juist zooals het overige gedeelte van Indonesië, uit een groot aantal kleine exclusieve adatrechtsgemeenschappen heeft bestaan, die ieder een eigen geschiedenis, adat en gebruiken en een daarmede overeenkomende eigen bestuur en administratie hebben gehad.

Toen naderhand door een monarch het vorstenbestuur over een bepaald territorium, bestaande uit een zeker aantal van die gemeenschappen, werd ingevoerd, zorgde zulk een monarch er voor, uit overwegingen van eigen belang, dat de verschillende gemeenschappen zooveel mogelijk ongerept bleven in hun eigen zeden en gewoonten; in hun adat. Vandaar dat er gedurende bijkans de geheele HinduJavaansche geschiedenis duidelijk twee bestuursordeningen te onderkennen zijn: 1e het desabestuur binnen iedere gemeenschap en $2 \mathrm{e}$ het vorstenbestuur als overkapping over de verschillende desabesturen. De eerste bestuursordening werd vertegenwoordigd door de dorpsouden - in de oorkonden de rāma's, tuha's, wahuta's of hoe zij verder mogen heeten ${ }^{11}$ ), bekend bij de opsomming der desa's of der grensgebieden (těpi-siring) - en de tweede werd vertegenwoordigd door den vorst en zijn staf van hoogwaardigheidsbekleeders, die wij hebben leeren kennen uit de zoogenaamde ,ambtenarenlijsten" ${ }^{12}$ ).

Dit dubbele karakter nu van bestuursordening missen wij in deze

9) B.v. O. J. O. II uit Çaka 731; K. O. XVIII uit Çaka 746 van een mahārāja Wagiswara en de oorkonden die Dr. R. Goris bespreekt in zijn aanteekeningen bij het artikel: „De inscriptie van Koeboeran Tjandi”, T. B. G. 70 (1930) blz. 160 sqq.

10) Cf. Dr. Goris 1.1. blz. 162.

11) Ibidem.

12) Het zijn deze ambtenarenlijsten die ons verschillende ongedateerde inscripties hebben helpen te identificeeren, doordat aan iedere bepaalde ambtenarenlijst, ook een bepaalde vorst of vorstendynastie, haerent is. De ambtenarenlijst uit Koning Balitung's tijd kan men vinden in Dr. Stutterheims' meergenoemd artikel : Een vrij overzetveer te Wanagiri, in T. B. G. 74 (1934). Uit Tulodong's en Wawa's tijd, P. V. v. Stein Callenfels: „Het Sindokraadsel opgelost” in O. V. 1919 blz. 68 sq. En uit de Tumapěl-Majapahit periode in mijn artikel „De Saptopapatti” in B. K. I. 90 (1933) blz. 239 sqq. Voor Bali zie men O. V. 1924 blz. 33. - Cf. de volgende noot 13 . 
oude oorkonden, om welke reden het misschien niet te gewaagd is te veronderstellen dat in dien ouden tijd van een vorstenheerschappij met centraal gezag over een groot territorium geen sprake was. $\mathrm{Al}$ worden de raka's i Panangkaran, Panunggalan, etc. allen Çrīmahārāja betiteld, het lijkt ons onwaarschijnlijk dat zij alleenheerschers waren over een gróót stuk van Midden-Java.

Eerst met Rakai Kayuwangi, de op Rakai Pikatan volgende vorst volgens de inscriptie uit de Kedoe, is het vorstenbestuur in de HinduJavaansche maatschappij van Midden-Java blijkbaar belangrijk meer geconsolideerd. De oorkonden van dezen vorst luiden de ambtenarenlijsten in, die nooit meer, op een enkele uitzondering na, zullen wegblijven van de oorkonden van latere vorsten tot aan het einde van de Hindu-Javaansche geschiedenis ${ }^{13}$ ).

Hebben wij tot nu toe (dus tot en met Rakai Kayuwangi's bewind) het vorstenbestuur allengs zien uitgroeien en hechter worden, met den volgenden vorst, Rakai Watuhumalang, schijnt de macht van de reeks van vorsten, die met Sañjaya begint, te tanen. Immers van het bestaan van Rakai Watuhumalang hebben wij slechts één enkel teeken n.l. in een oorkonde, niet van hem zelf uitgaande, waarin sprake is van ,haji Rakai Watuhumalang” ${ }^{14}$ ).

Wat te denken van dit poovere teeken van zijn bestaan? Zou het louter toeval zijn dat wij van hem zoo weinig over hebben, terwijl zijn voorganger Rakai Kayuwangi een zoo'n hecht bewind voer blijkens de oorkonden uit zijn tijd?

Hebben wij waarschijnlijk de oorzaak elders te zoeken? Is het niet denkbaar, dat tijdens Watuhumalang's regeering er onrust in zijn land heerschte, zoozeer dat wij van dezen vorst weinig vernemen in tegenstelling met andere vorsten of regeerders, die wel van zich hebben laten hooren ${ }^{15}$ ); en dat van deze algemeene verwarring de

13) Koning rake Kayuwangi's ambtenarenlijst is gedurende zijn regeering blijkbaar niet noemenswaardig veranderd. Zie O. J. O. XII a5-8; K. O. XIV a2-5; K. O. XV a8-12. De op deze plaatsen genoemde titels der hoogwaardigheidsbekleeders komen overeen met die op een oorkonde van koning Kayuwangi's vermoedelijken voorganger (zie oorkonde van de Kĕdoe T. B. G. 67, blz. 189) rake Pikatan, tenminste wat betreft het eerste gedeelte dier titels; het gedeelte achter ,pu" is verschillend.

14) K. O. IX, b. 4, 5.

15) Çri Kahulunan, van wien wij twee oorkonden over hebben, uit 796 Çaka (O. J. O. X) en uit 806 Çaka (O. J. O. XVII), die dus een tijdgenoot geweest kan zijn van den raka i Pikatan, i Kayunwangi en i Watuhumalang, is mogelijk zulk een onafhankelijke grootheid. De inhoud van zijn oorkonden maakt op ons den indruk, dat deze inscripties apart staan. Cf. nog Prof. Krom's Hindu- 
usurpator uit het Oosten gebruik heeft gemaakt om zijn macht ook over Midden-Java uit te strekken? Dit is Balitung dan schitterend gelukt. Zijn vele oorkonden op verschillende plaatsen in Oost- en Midden-Java gevonden, getuigen hiervan.

Wat betreft onze koperen platen - fragmenten van twee verschillende oorkonden ${ }^{16}$ ) - moge thans over den inhoud daarvan eenige aanteekeningen gemaakt worden.

\section{Dateering.}

Oorkonde I heeft als datum 829 Çaka; van oorkonde II echter is het begin en dus hiermede ook het jaartal verloren geraakt. Het voorkomen van „Çrī Mahārāja Raka i Watukura”, Z.M. de Grootkoning, Heer van Schildpadsteen, brengt ons in den tijd van Balitung en aangezien de ons bekende oorkonden van dezen vorst het tijdvak van 820 Çaka tot en met 832 Çaka omvatten ${ }^{17}$ ), moet onze oorkonde uit deze periode afkomstig zijn.

Misschien mogen wij deze tijdruimte iets meer beperken door gebruik te maken van de verschillende lezingen der vervloekingsformulieren.

Bekend is, dat deze vervloekingsformulieren en de beschrijving der ceremonie, hierbij in acht genomen, in de oudste oorkonden beknopt en hoe langer hoe meer wijdloopig worden, naar mate men met een jongere inscriptie te doen heeft. Met het klimmen der jaren merkt men hiervan een gestadige uitbreiding op. In de oudste oorkonden $\mathrm{nu}$, worden geen goden en hoogere wezens tot getuigen geroepen. Daar komen slechts vervloekingen in voor, hierop neerkomende, dat alwie zich niet houdt aan de bepalingen vervat in de oorkonde in kwestie, een groot ongeluk zal treffen, hier op aarde of in het hiernamaals ${ }^{18}$ ) (mangguha duhka magěng of pañcamahāpātaka). In de oudste inscripties van Balitung blijft deze lezing nagenoeg onveranderd. Deze inscripties zijn die van Panaraga, van Çaka 823 (O. J. O. 23), Kembang Aroem van 824-825 Çaka (O. V. 1925, bl. 41), Wanagiri van Çaka 825 (T. B. G. 74, bl. 269). Hierin is sprake slechts van de pañcamahāpātaka. De in jaren hierop volgende oorkonde, waarin een vervloekingsformulier voorkomt, is die uit de Kedoe van Çaka 829 (T. B. G. 67, bl. 73). En dit is het eerste uitgebreide formulier

Javaansche geschiedenis, blz. 182, waar andere vorsten genoemd worden die „buiten de reeks" vallen.

16) In de „Aanwinsten” 1934, blz. 136, heb ik hierop gewezen.

17) Vide het lijstje op blz. 274 van T.B. G. 74.

18) Vide b.v. O. J. O. IX, IIa einde; O. J. O. XI; O. J. O. XII, b. 13. 
dat wij in de oorkonden zijn tegengekomen. Het is zelfs een buitengewoon wijdloopige, waarbij vele soorten van hoogere wezens tot getuigen worden geroepen, onder welke b.v. ook de bekende reeks van gelukzalige, reeds overleden vorsten, die aanvangt met Sañjaya en eindigt met den koning Raka i Watuhumalang, in voorkomt.

„Indah kamung hyang....” luiden de openingswoorden, waarbij „hyang" het bekende pronomen is ter inleiding van de er op volgende hoogere wezens. Het vervloekingsformulier nu, voorkomende in onze oorkonde (II B 2-7), is een van de laatste soort, een uitgebreide, met aanroeping der hoogere wezens. Wij kunnen dus voorloopig aannemen dat de datum van oorkonde II tusschen 825 en 833 Çaka in ligt, aangezien 825 het jaar van de laatste oorkonde met een korte vervloekingsformule is en omdat tot heden toe nog geen oorkonde van Balitung gevonden is, jonger dan 832 .

\section{De voornaamste eigennamen en de vrijstiften.}

Hoe in de Hindu-Javaansche maatschappij de namen van den apanagehouder zich verhouden tot die van het apanage, is altijd nog een open vraag ${ }^{19}$ ). Zoo hebben wij als begunstigde op oorkonde I, samgat Lamwa pu Layang, die het landschap Sang-Sang af te bakenen krijgt en op oorkonde II, samgat Kalangwungkal pu Layang, die de landschappen Wakujana, Tumpang en Wurutlu af te bakenen krijgt. Duidt het ,pu Layang” één en dezelfde persoon aan, genoemd naar twee verschillende apanages: Lamwa en Kalangwungkal? Dr. Stutterheim zegt ,dat wel de naam achter het rakai ${ }^{20}$ ) kan wisselen bij één en dezelfde persoon, doch niet die achter dyah of pu" ${ }^{21}$ ). Verder zij de aandacht gevestigd op het feit dat de bekende vorst Tulodong een raka i Layang is.

In oorkonde I staat vermeld dat het af te bakenen gebied SangSang beheerd. zal worden (punpunana) door het klooster (wihāra) Hujung Galuh (I A 5, 6) en in oorkonde II de landschappen Wukajana, Wurutělu en Tumpang door het klooster Dalinnan (II B 8). Hujung Galuh en Dalinan zijn in de Hindu-Javaansche epigraphie geen onbekende klanken.

De eerste naam komt veel voor in oorkonden, zoowel van Midden-

19) Vide Dr. Stutterheim's studies over dit onderwerp b.v. in T: B. G. 67 in meergenoemd artikel over de oorkonde uit de Kĕdoe en in T. B. G. 73 (1933), blz. 159 sqq : „Iets over raka en rakryān....”.

20) Hetgeen over rakai wordt gezegd geldt, dunkt ons, ook voor samgat. Waarschijnlijk is samgat een lagere ,titel” dan rakai.

21) „Een belangrijke oorkonde uit de Kĕdoe” (T. B. G. 67, blz. 180, 181). 
Java ${ }^{22}$ ) als ook van Oost-Java ${ }^{23}$ ), doch hier als deel van een persoonsnaam of titel: parujar i sirikan Hujung Galuh. In onze oorkonde I is Hujung Galuh de naam van een klooster, dat, zooals wij straks zullen zien, zeer klaarblijkelijk ergens op Midden-Java gelegen moet hebben. De plaatsnaam Hujung Galuh in O. J. O. LXI, die terecht op Oost-Java is gelocaliseerd ${ }^{24}$ ), is niet hieraan gelijk.

De naam van het klooster Dalinan op oorkonde II is bekend uit ettelijke Midden-Javaansche oorkonden, óók als persoonsnaam of titel: Dalinan pu Acung ${ }^{25}$ ). Het is niet uitgesloten dat van deze beide plaatsnamen in onze oorkonden, de titels zijn afgeleid; waarschijnlijk oorspronkelijk als apanage-aanduiders. Straks zullen wij terugkomen op de twee kloosters, die deze namen dragen.

Behalve dat de naam Layang ons in een Midden-Javaansche sfeer brengt ${ }^{26}$ ), blijkt de plaatsnaam Kilipan (Oorkonde I B, 15) ook voor te komen in de oorkonde van Kembang Aroem. Bovendien zal een Wuru tunggal van de oorkonde van Kembang Aroem ${ }^{27}$ ) - dus uit Midden-Java - toch zeker niet ver uit de buurt hebben gelegen van Wuru tělu (oorkonde II). Misschien mogen wij uit deze coincidenties de gevolgtrekking maken dat de plaatsen genoemd in onze oorkonde, gelegen hebben in dezelfde streek als de plaatsen uit de inscriptie van Kembang Aroem. Wij willen er nog even op wijzen dat de oorkonde uit het museum te Solo ook ettelijke gelijkluidende namen vermeldt: Kalangwungkal, Dalinan, Kilipan en Patapān ${ }^{28}$ ). Handelt deze soms ook over dezelfde streek?

Zooeven spraken wij terloops over de localisatie van de kloosters Hujung Galuh en Dalinan op Midden-Java. Gaan wij thans dieper op dit onderwerp in.

Van oorkonde I luidt de „sambhanda” (A, regel 5-7): „De aanleiding ervan dat gelast werd om dat landschap af te bakenen: er is een kuti te Hujung Galuh, ressorteerend onder Lamwa. Dit nu werd hersteld door den ambtenaar Lamwa, het werd door hem ver-

22) De oorkonde van Kembang Aroem in O. V. 1925, bl. 42 en in K. O. I, die waarschijnliik ook uit Midden-Java afkomstig is.

23) O. J. O. XXXI, XXXVIII en XLIII.

24) Krom, Hindu-Javaansche Geschiedenis, blz. 266.

25) B.v. K. O. XIV en XV, en O.J.O. XII; in de inscriptie van Solo in O. V. 1922 , blz. 85 regel 4 komt het voor als plaatsnaam.

26) Cf. O. J. O. XXXVI, blz. 57 regel 12 ; K. O. IX, 1 b. 4; K. O. XVII, $2,16,18,23,27$, die alle uit Midden-Java afkomstig zijn.

27) O. V. 1925 , blz. 42, II, 3.

28) Voor Patapān als plaatsnaam vide Stutterheim in T. B. G. 67, blz. 175, noot 4 . 
fraaid, het werd door hem ,gezegend” (jinayyakan) met een wihāra. Dit is de aanleiding er van dat een gunst bewezen werd, n.l. dat gelast werd het landschap Sangsang af te bakenen tot een vrijstift, beheerd door deze wihāra, welke een stichting is van hem (van Lamwa)". Uit regel B. 8 van oorkonde II blijkt dat samgat Kalangwunkal pu Layang de drie streken Wakujana, Tumpang en Wurutělu als privilege kreeg omdat de „bihāra i Dalinnan zijn stichting is".

De in beide oorkonden genoemde stichtingen nu zijn Buddhistisch, omdat zij kuți en wihāra genoemd worden, welke, op Java althans, zeer klaarblijkelijk benamingen waren voor speciaal Buddhistische heiligdommen.

$\mathrm{Er}$ is, voor zoover ik het heb kunnen nagaan, nog nooit een ernstige poging gedaan om de woorden die in de Oud-Javaansche litteratuur gebruikt worden om gebouwen of heiligdommen aan te duiden op hun rechte waarde te schatten. Kuți b.v., dat niet zelden voorkomt in de Nāgarakrtãgama placht Kern in zijn vertaling weer te geven nu eens met: (monniks-) kluis ${ }^{29}$ ), monnikenverblijf ${ }^{30}$ ), dàn weer met klooster of monnikshut ${ }^{31}$ ). Terwijl Zhgl. wihāra óók klooster noemt ${ }^{32}$ ). Kalagyan wordt in de Ngkṛt. vertaald met: tijdelijk kluizenaarsverblijf ${ }^{33}$ ).

Waar het op aan komt is, om deze heiligdommen te onderscheiden naar de verschillende religieuze gemeenschappen tot welke zij resp. behoorden. Hiervoor vindt men een aanwijzing in de Ngkṛt. Zang 75, vers 2. Daar heet 't dat den Çaiwādhyakșa de bescherming werd opgedragen van de parhyangan's en de kalagyan's, de Boddhādhyakșa te waken had over de kutị's en wihāra's, en de mantri her-haji over de Karěșyan's. Hieruit valt te concludeeren dat parhyangan en kalagyan Çiwaïtische-, en kuți en wihāra Buddhistische heiligdommen waren. Dit gegeven uit de Ngkrt. vindt steun in Zang 30 vers 1 en 2 van de kakawin Arjuna Wijaya $\left.{ }^{34}\right)$ : „Kaboddhan ika boddha sang sungana dharma kuți kuți lěpas kașadpādan; kaçaiwan ika çaiwa sang sungana tasyan angalapa kalāgyan uttama; karěșyan ika walkalīka sira sang sungana saphala ring wanāçrama". Met andere woorden de

29) Ngkṛt. Zang 17 vers 10 en 11.

30) Ngkrt. Zang 19 vers 1 ; Zang 20 vers 1 .

31) Ngkṛt. Zang 35 vers 2; Zang 62 vers 1 ; Zang 75 vers 2; Zang 79 vers 1.

32) Ngkrit. Zang 75 vers 2; Zang 80 vers 1 .

33) Ngkṛt. Zang 75 vers 2; Zang 79 vers 1 .

34) Ms. Or. 4067 uit het Legatum Warnerianum. Catalogus Juynboll. I., blz. 136. 
heiligdommen van de 1 çaiwa, 2 boddha, 3 rěși - de bekende trits uit de Hindu-Javaansche litteratuur - blijken te heeten respectievelijk: 1 parhyangan en kalagyan, 2 kuṭi en wihāra, 3 āçrama. Vragen wij ons af of Prapañca in zijn gedicht deze woorden consequent in de zoo juist genoemde beteekenissen gebruikt heeft, dan blijkt het antwoord te zijn een volmondig ,ja”. Immers in de Ngkṛt. is kuṭi Ratnapangkaja (Z. 17, vers 10) een Buddhistisch heiligdom en wel volgens $Z$. 20, vers 2 alwaar deze stichting heet te ressorteeren onder de deça kasogatan. De ,kuți mangaran ring Ḍarbaru” (Z. 35, vers 2) werd officieel (cf. de volgende strophe) door Prapañca, in zijn functie van dharmādhyakșa ring kasogatan bezocht. In Z. 62, vers 1 blijkt de ,kuți ring Gurung-gurung” aan de gemeente van de bajradharasekte der Buddhisten te behooren ${ }^{35}$ ). En tenslotte kan hetzelfde gezegd worden van de in $Z$. 80, vers 1 voorkomende Balische kuți en wihāra. Wat de Çiwaïtische heiligdommen betreft, een parhyangan, Kuți-jāti geheeten, behoort volgens Z. 76, vers 1 tot de „dharma lěpas pratișta Çiwa” ${ }^{36}$ ). En als derde van de trits vinden wij in de Ngkrt. de āçrama ri Sāgara genoemd als een heiligdom der mahārěși's (Z. 32, vers 2 en 6 ; Z. 33, vers 1 ).

Wat betreft de Hindu-Javaansche oorkonden, ook daar blijkt hetzelfde onderscheid gehandhaafd te zijn. In O. J. O. LV uit 888 Çaka welke o.m. aan de openingswoorden "Namostu sarwwabuddhaya” kennelijk als een Buddhistisch getinte oorkonde te beschouwen is, wordt de stichting er kuti ${ }^{37}$ ) genoemd en in de oorkonde voorkomende in het O. V. van 1924, blz. 26, waarin gesproken wordt over ,sang hyang tathāgata” en ,ratnatraya” - typisch Buddhistische klanken - heet het vrijstift een „kuți”, ressorteerend onder „Gandhakoți wihāra". Een voorbeeld van een Çiwaitische stichting, die parhyangan genoemd wordt, levert O. J. O. LVII regel 6. Deze is de bekende oorkonde uit Çaka 913 waarin een ,sang hyang Çiwaçāsana” genoemd wordt, en die daarom ook in Çiwaïtische omgeving thuis hoort. Nog een voorbeeld hiervan geeft O.J. O. LXXIX. Deze oorkonde eindigt met de woorden „ọ̣ namaçiwāya” en handelt over „al de stichtingen" (sarwa dharma) speciaal van de Çiwaitische gemeenten

35) Prof. Kern's vertaling van regel 4 van Zang 62 vers 1 is niet juist; ik volg Dr. Poerbatjaraka's interpretatie. Cf. B. K. I. 80, blz. 244.

36) Het in Zang 76 regel 1 voorkomende Kuți Balay past schijnbaar niet in ons betoog, daar hier sprake is van Çiwaitische heiligdommen. Doch zooals Poerbatjaraka het ook deze keer beter weergeeft, is Kuți Balay een plaatsnaam. Cf. B. K. I. 80, blz. 263.

37) O. J. O. LV b. 1. 
blijkens het feit dat in de ambtenarenlijst alléén de Çiwaitische hoogwaardigheidsbekleeders voorkomen en de Buddhistische in dit geval klaarblijkelijk er niet in betrokken werden, daar zij er niets te maken hadden $\left.{ }^{38}\right)$. ,Al de stichtingen” nu bestaan uit ,paryyangan's” en „kalagyan's”. En tenslotte de heiligdommen der ṛ̣i-gemeente - de karșyan dus. Dat deze bij voorkeur āçrama's genoemd worden, ervaren wij uit de oorkonde, die door Dr. Stutterheim in T. B. G. 65 (1925) is uitgegeven, vertaald en van een bespreking voorzien: „Een oorkonde op koper uit het Singasarische". Hierin toch wordt melding gemaakt van een schenking aan ,sang hyang dharmmaçrama patapan i Pawitra" ${ }^{39}$ ). Deze āçrama te Pawitra behoort tot de karșyan van denzelfden naam, genoemd in de Nāgarakrtāgama Zang 58, vers 1 en zang 78 vers $1^{40}$ ). Opgemerkt dient nog dat uit deze oorkonde blijkt dat het zuiver Sanskṛt āçrama gelijk is aan het van Sanskṛtorigine, verjavaanschte patapan ${ }^{41}$ ). Trouwens op de z.g. steeninscriptie van Calcutta wordt het ,āçrama” van het Sanskṛt-gedeelte vertaald met ,patapan” in het Javaansche fragment ${ }^{42}$ ). Ook dèze āçrama of patapan is, zooals wij zien uit regel 4 van den Javaanschen tekst van den steen van Calcutta een onderdeel van een ,dharmma karsyan".

Wij mogen, waar de gegevens overal zoo goed harmonieeren, dus besluiten, dat het gerechtvaardigd is om zich te houden aan de boven geciteerde mededeeling uit de kakawin Arjuna Wijaya en Nāgarakrtāgama; en dat in den Hindu-Javaansehen tijd men

de Buddhistische heiligdommen: kuți en wihära

de Çiwaïtische heiligdommen: parhyangan en kalagyan

de heiligdommen der rși's : āçrama en patapan placht te noemen.

In onze beide oorkonden zijn dus de kuți en wihāra te Hujung Galuh en de bihāra ( $=$ wihāra) te Dalinnan stellig Buddhistische stichtingen.

38) Of omdat het college van Buddhistische upapati's in Çaka 1191 - het jaartal van de oorkonde in kwestie - nog niet bestond. Cf. van Naerssen: De Saptopapatti, B. K. I. 90, blz. 250-251.

39) Koperplaat Ia regel 5 en op blz. 235 regel 19.

40) Vide Stutterheim 1.1. blz. 222.

41) Men vergelijke in Stutterheim's meer genoemd artikel de koperplaat IIa, regel 3 met de hieraan gelijke passage op de steenoorkonde, regel 19 (blz. 235), alwaar klaarblijkelijk het woord āçrama vertaald wordt in een explicatieve samenstelling met patapān. Cfr. evenzoo koperplaat Ia, regel 5 met steenoorkonde, regel 7 op blz. 232.

42) Men vergelijke in Kern's Verspreide Geschriften deel VII, blz. 101, regel 32 en 33 met blz. 106, regel 37, 38, 40, 43 etc. 
In de notulen van het Bataviaasch Genootschap van 1920 schrijft Dr. Bosch op blz. 54 naar aanleiding van ,Het steenen zuiltje van Kadiloewih" o.m. dat eenige plaatsnamen voorkomende in de $3 \mathrm{e}$ strophe van den 77 sten zang uit de Nāgarakṛtāgama, in Midden-Java te localiseeren zijn. In deze strophe worden de volgende plaatsen opgesomd: Buḍur, Wwirun, Wungkulur, Mananggung, Watukura, Bajrāsana, Pajambayan, Samalantěn, Simapura, Tambak laleyan, Pilanggu, Pohaji, Wangkali, Běru, Lěmbah, Dalinan, Pangadwan. Bosch heeft in zijn bovengenoemd artikel aannemelijk gemaakt dat Budur te identificeeren is met de wereldberoemde Boroboedoer en dat ook Mananggung in Midden-Java heeft gelegen. Stutterheim localiseert in deze omgeving bovendien nog met stelligheid: Watukura, Wungkulur (= Wungkudur) en Dalinan, en onder voorbehoud: Simapura (= Singhapura), Wangkal(i) en Pilang ${ }^{43}$ ).

Onze oorkonden zijn zeer waarschijnlijk uit Midden-Java afkomstig; ten eerste volgens de mededeeling van den gewezen eigenaar er van, ten tweede omdat de er in genoemde plaatsnamen bekend zijn uit andere oorkonden van Midden-Java ${ }^{44}$ ), en ten derde, omdat, althans in oorkonde I, Balitung zijn Midden-Javaanschen titel draagt: „Çrī dharmmodaya mahāsambu" ${ }^{45}$ ). Hieruit is dus de gevolgtrekking te maken dat inderdaad Dalinnan, waar zich de wihāra bevindt uit de oorkonde, hetzelfde is als het eveneens Buddhistische Dalinan uit de Nāgarakrtāgama. Voorts valt in overweging te nemen om Wuru tlu (de drie Wuru's) te identificeeren met Bĕru uit het gedicht, en misschien ook nog de streek Lamwa, waaronder Sangsang en de kuṭi Hujung Galuh ressorteeren met Lĕmbah, waarbij men rekening heeft te houden met het verschijnsel dat in het Javaansch een woord uitgaande op een vocaal gemakkelijk een $h$ als afsluiter er bij kan krijgen ${ }^{46}$ ).

Oorkonde II heeft een uitvoerige beschrijving van de plechtigheden en feestelijkheden bij de hoogheilige watu-kulumpang. De begunstigde, de samgat Kalangwungkal is bij deze plechtigheid vergezeld van zijn vier echtgenooten n.l. de samgat anakbi dyah Sucintě, dyạ̣ Kina, dyah Waita en dyah Sawitā. Opmerkenswaard is dat zij ieder een eigen dyah-naam hebben en alle vier naar het blijkt het praedicaat samgat (II A 12); misschien van hun echtgenoot samgat Kalangwung-

43) T. B. G. 67, blz. 182, 183.

44) Cfr. blz. 451 hiervóór.

45) Vide Stutterheim in T. B. G. 74, blz. 273-274.

46) B.v. nieuw-Javaansch Ngoko „lila” = Krama „lilaḥ”. 
kal? Zooals de gade van Balitung's opvolger, koning Dakșa rakai Hino, ook rakryan binihaji parameçwarī wordt genoemd ${ }^{47}$ ).

\section{De plechtigheden om de hoogheilige Watu Kulumpang.}

Deze oorkonde II is de derde van de Hindu-Javaansche inscripties die de feestelijkheden zoo uitvoerig behandelt, dat zelfs de groepeering om de hoogheilige watu-kulumpang is beschreven ${ }^{48}$ ). Op II, A 12B 1 lezen wij : ,nadat den woordvoerders de vijf eeregeschenken gegeven waren, tooiden zij zich met bloemen en blanketsel; zij gingen zich verplaatsen. $\mathrm{Zij}$ verhieven zich en richtten zich naar de overdekte feestplaats (witāna), waar de plechtigheden zouden plaats hebben, (de plaats waar ge-,,uyut" werd), daar gingen zij zitten naar het Zuiden gekeerd, met het gezicht gewend naar de hoogheilige kudur. De wahuta hyang kudur ging(en) zitten gekeerd naar het Oosten. Evenzoo ging(en) de patih wahuta zitten achter de wahuta hyang kudur. De rāma's van Wukjana, van Tumpang, van Wurutĕlu en de rāma's van de grensgebieden, zij allen gingen zitten met het gezicht gekeerd naar het Noorden. De matrônes (rainanta) gingen zitten in het Oosten van de overdekte feestplaats, het gezicht gekeerd naar het Westen".

Wanneer wij deze groepeering vergelijken met die, beschreven in de twee andere oorkonden (zie noot 48), dan zullen wij zien dat er veel overeenkomst bestaat tusschen deze drie beschrijvingen van ,de wijze van zitten der aanwezigen.

De hier volgende tabel geeft een overzicht daarvan:

\begin{tabular}{|c|c|c|c|c|}
\hline Ọorkonde van: & In het Noorden: & In het Westen: & In het Zuiden: & In het Oosten : \\
\hline Amsterdam II & $\begin{array}{l}\text { sang mamuat } \\
\text { ujar. }\end{array}$ & $\begin{array}{l}\text { sang wahuta hyang } \\
\text { kudur, sang patih } \\
\text { wahuta }\end{array}$ & $\begin{array}{l}\text { rāma i Wukajana, } \\
\text { i Tumpang, i Wu- } \\
\text { rutlu, rāma těpi- } \\
\text { siring. }\end{array}$ & raiṇanta. \\
\hline $\begin{array}{l}\text { Kĕmbang } \\
\text { Aroem (O. V. } \\
\text { 1925, blz. } 41 \\
\text { sqq). }\end{array}$ & $\begin{array}{l}\text { sang pamagat } \\
\text { Pikatan, rake } \\
\text { Wantil, samagat } \\
\text { Manungkuli. }\end{array}$ & $\begin{array}{l}\text { sang wahuta hyang } \\
\text { kudur, sang tuhan } \\
\text { mamuat wuwus. }\end{array}$ & $\begin{array}{l}\text { sang wahuta patih̆, } \\
\text { rāmanta, anak wa- } \\
\text { nua těpi-siring (cf. } \\
\text { O.V. } 1925 \text {, blz. } 48 . \text { ) }\end{array}$ & \\
\hline $\begin{array}{l}\text { Tuloḍong } \\
\text { (K. O. I.). }\end{array}$ & $\begin{array}{l}\text { sang } \\
\text { prãgwiwaka }\end{array}$ & $\begin{array}{l}\text { sang wahuta hyang } \\
\text { kudur. }\end{array}$ & $\begin{array}{l}\text { patih̆, rāma, rarai, } \\
\text { matuha, laki-laki, } \\
\text { waduan. }\end{array}$ & \\
\hline
\end{tabular}

47) O. J. O. XXX voorzijde 30. Cf. Prof. Krom's Hindu-Javaansche geschiedenis, blz. 193.

48) Wij hebben, behalve op deze oorkonde II van Amsterdam, zulk een be- 
De plaats van de wahuta hyang kudur is steeds aan den westkant van de overdekte plaats (witāna). In het Zuiden plachten de functionarissen der dorpen zoowel van die welke afgebakend werden, als van de grensgebieden, te zitten. In het Oosten zaten de rainanta's of matrônes, althans volgens oorkonde II. In beide andere oorkonden (K. O. I en die van Kĕmbang Aroem) komt deze zijde van de witāna niet ter sprake. De vrouwen (alleen van de functionarissen der grensdorpen?) werden in het Zuiden ondergebracht. In het Noorden hadden de woordvoerders hun plaatsen, volgens oorkonde II en de oorkonde K. O. I. In deze oorkonde worden zij respectievelijk ,,sang mamuat ujar" en „prāgwiwāka” ${ }^{49}$ ) genoemd. Hierbij zij opgemerkt dat in de veel jongere inscripties van de Tumapĕl-Majapahit periode, de dharmādhyakșa's en de upapati's, prāgwiwāka heeten te zijn. Is het misschien mogelijk dat de dharmādhyakșa's en upapati's dezelfde werkzaamheden hadden als de parujar's van weleer?

Op de oorkonde van Kembang Aroem hebben de woordvoerders (tuhan mamuat wuwus; wuwus $=$ ujar) plaats moeten maken voor den stichter van het vrijgebied en zijn medewerkers ${ }^{50}$ ). Eerstgenoemden hebben een plaats gekregen in het Westen, bij de wahuta hyang kudur.

Samenvattend vertoont de groepeering om de watu kulumpang in groote trekken het volgende beeld. Het Noorden is de plaats voor de groote Heeren apanagebezitters, of bij ontstentenis van hen, voor hun woordvoerders; het Westen is de plaats gereserveerd voor de dienaren van den eeredienst; het Zuiden voor de hoofden der desagemeenschappen en hun familie en het Oosten, vermoedelijk niet altijd, voor de getrouwde vrouwen ${ }^{51}$ ).

\section{De ceremoniëele feestelijkheden.}

De plechtigheid om den wijdingssteen werd besloten met het uitspreken van het eedformulier (II B $1-8$ ), daarna vonden de feestelijkheden plaats bestaande uit muziek, spel en dans ${ }^{52}$ ).

Het is moeilijk te zeggen of de eigennamen bij personen behooren,

schrijving gevonden op de oorkonde van Kĕmbang Aroem in O. V. 1925, blz. 41 sqq. en in de oorkonde van koning Tulodong, in K. O. I.

49) In Dr. A. B. Cohen Stuart's „Kawi oorkonden. Inleiding en Transscriptie”, blz. 5; I, 3, 13 staat getranscribeerd „prāwitaka ('gwi?)”. Bij raadpleging van het bij deze inscriptie behoorende facsimile valt echter heel duidelijk te lezen „prāgwiwaka".

50) Vide O. V. 1925, blz. 47, 48.

51) Cf. Dr. F. D. K. Bosch, De oorkonde van Kĕmbang Aroem, O. V. 1925, blz. 49.

52) Vermoedelijk óók uit een maaltijd, zooals deze op andere oorkonden 
of wel titels zijn van verschillende spelen. Duidelijk is, dat er kijkspelen (ton-tonan) waren, dat er gezongen (mamidu), gereciteerd (macarita), gedanst (mangigĕl) en tooneel gespeeld (mamirus) werd, waarbij het potsenmaken (mabañol) de note gaie was. Ter eere van de godheid werd een wayang vertooning opgevoerd (II B 9, 10). Wat op de laatste regel staat is niet duidelijk te lezen en ook niet goed te verstaan. De feestvierders schijnen zich te vermaken met dobbelen (pamuat toh; cf Nieuw-Javaansch : botoh) en met ,,makarungakan". In O.J. O. XXIII, 6 lezen wij bij de beschrijving van een feestviering, óók ter gelegenheid van een landschenking, dat men maaltijden en drinkfestijnen houdt, zich met bloemen en blanketsel siert, schijngevechten houdt, danst en ,manawung karung hayam”, hetgeen waarschijnlijk beteekent : ,men liet vechten zwijnen en hanen”. Zou in onze oorkonde misschien ,makarungakan” ook ,zwijnengevechten houden" beteekenen, waarbij zooals bij de hanengevechten duchtig gedobbeld werd?

Treffend is de overeenkomst tusschen de beschrijvingen van dergelijke feesten zooals die voorkomen op de oorkonden en in de OudJavaansche poëzie- en prozawerken. Men vergelijke deze scène van onze oorkonde met b.v. zang 91 van de Nāgarakrtāgama (ed. Kern) of met het begin van het Oud-Javaansche Brahmāṇda-purāna (ed. Gonda). Gelijkluidend zijn de namen der spelen, dansen en muziekinstrumenten. In de Sumanasāntaka-Kakawin (volgens v. d. Tuuk's K.-B. woordenboek s.v. tangkil, zang 113; volgens het ms. uit het Legatum Warnerianum No. Or. 4519 zang 106 of 107) wordt zulk een feestviering bij gelegenheid van het huwelijk eens vorstenpaar beschreven en wel als volgt:

1. Ri uwusira těkêng paprasan bwat sura nāgara

Sa ana-ana nikang wwang bhaktya ngañjali ri sira

Pasaji ri sira ampyal dantâçrī sira $\mathrm{n}$ apupul

Kadi surapati sangkêng swarga mwang suramahasi.

2. T ucapa alěp ikang paprasan dug sira winarang

Kadi umaras awimba hyang Candrârka winulatan.

Těka ring alun-alun sěh lungsir inatěpakĕn

Pada kadi gunung apuy muntab de ning angin adrĕs.

3. Rasa bubula tĕngah ning rājya apn pada gumĕrĕh.

Para ratu saha gěnding gong rojeh taběh-taběhan.

beschreven wordt. Oorkonde II heeft waarschijnlijk zulk een beschrijving op een verloren geraakte plaat. 
Apituwi para tanda srang-srangan midĕr aritan Saha padahi gumĕntèr lagyatryasurak angawat.

4. Para widu sědĕng aywan sang tangkil hyang acarita, Pada gumuyu kapuhan sakweh ning widu binisa.

Ana kawatěk ujarnya n guywawarna macarita:

Uduh uduh uduh ah ah ah ah ah ah, bisa dahatĕn.

5. Sa-ana ning abañol denyângguywakěna puraci Angigěl-igěl agěng-gĕngan kontol pada mĕtĕtĕng Wělu sakěběh agasyak ndan moghâwědi wĕkasan Kaguyu-guyu kagěman yan prāpta ng wělu sabatang.

6. Pirus amirusi men-men denyamet pacěh acěměh, Rabi nika bisa pantěs denya bhāwaka mangěyĕh Laki nika mulata ng drĕng kahyun-hyun angungas-ungas Kadi wědus anut anjyan yan tĕngat kamuringis ${ }^{53}$ ).

Het is noodeloos om punt voor punt op de vele overeenkomsten met de beschrijving in de oorkonden te wijzen. Men vergelijke slechts dit citaat met onze inscripties hiervóór.

Naar aanleiding van het woord pirus, dat zoowel in het laatste vers van het geciteerde gedeelte van de Sumanasāntaka voorkomt, alsook in oorkonde II, B 10 in den vorm van mamirus, schrijft Mr. J. Kunst ${ }^{54}$ ): „Van der Tuuk leidt dit woord waarvoor hij één locus opgeeft doch dat verder nog vrij dikwijls in oorkonden wordt aangetroffen - af van Skrt. pipirușa, dat fluiten zou beteekenen en dat eenmaal in het Rāmāyana ${ }^{55}$ ) voorkomt. Het wil mij toeschijnen, dat men niettemin aan pirus geen instrumentale beteekenis moet hechten en wel, omdat het weer in de ,wayanggroep” der verboden handelingen voorkomt en niet in de, even te voren genoemde, ,muziekgroep”.

Onder de „muziekgroep” verstaat Kunst de in de Balineesche oorkonden genoemde musici (anuling, amukul, agẹṇ̣ing e.a.) en onder de ,wajanggroep” de lieden, die onmiddellijk na de musici opgesomd worden en van wie gezegd wordt dat zij ,men-men", ,,aringgit”, ,,abañwal” etc. „De opvatting, dat met pirus een of ander tooneelspel of potsenmakerij is aangeduid", zoo gaat bovengenoemde auteur verder, ,vindt bovendien nog ondersteuning in het feit, dat

53) $\mathrm{Bij}$ het transcribeeren dezer versregels is geen rekening gehouden met de prosodie.

54) In „Hindu-Javaansche muziek-instrumenten speciaal die van Oost-Java” [Batavia] 1927, blz. 40.

55) Rāmāyaṇa-kakawin ed. Kern. Zang XXIV, 106. 
men (ook bij Van der Tuuk) als Balische vertaling van het woord opgegeven vindt: njĕmarin, d.i.: voor Sĕmar spelen, den rol van Sěmar vervullen".

Prof. Berg is middels woordvergelijking tot hetzelfde resultaat gekomen.

Bekend is de ontwikkeling $\vee$ dirus (Maleisch berdirus $=$ begieten) $>\vee d i$-us of $\vee$ dyus (= Oud-Jav. baden) $>\vee d u s$ (Nieuw-Jav., adus baden). Evenzoo moet de ontwikkeling zijn van $\vee$ pirus $>\vee$ pi-us of $\checkmark$ pyus $>\vee$ pus. Dit laatste bestaat nog in het Nieuw-Javaansch als adjectief apus, in de beteekenis van bedriegen, voor den gek houden, verleiden, bekoren, m.a.w. het Oud-Javaansche pirus, dat thans niet meer bestaat, moet een ongeveer gelijke beteekenis hebben, dus als substantief - tooneelspeler of voordrachtkunstenaar, iemand die het publiek voor den gek houdt met zijn grappen (of met zijn masker?) of, in het algemeen, iemand die met zijn kunst het publiek weet te bekoren ${ }^{56}$ ).

In de krtabasa-pericope van de Candakarana ${ }^{57}$ ) nu vindt $\mathrm{Mr}$. Kunst's vermoeden en Prof. Berg's hypothese bevestiging.

Op pag. 48 van het Ms. heb ik de volgende verklaring gevonden: „,kuçilawa ngarañya pirus” m.a.w. het Sanskṛt kuçilawa, dat volgens het St. Petrusburger woordenboek, „Barde, Schauspieler” beteekent, wordt door den Oud-Javaanschen auteur gelijk gesteld met ons woord pirus. Hiermede is komen vast te staan dat $V$ pirus niets te maken heeft met fluiten, maar met tooneel- of voordrachtspel.

Wat ,pipirușa" betreft, het woord, dat voorkomt in het OudJavaansche Rāmāyaṇa Zang 24, vers 106 en dat volgens Van der Tuuk ${ }^{58}$ ) het Sanskrrt origineel zou moeten zijn waarvan pirus is afgeleid, dit woord heb ik niet kunnen vinden in het St. Petrusburger woordenboek.

Mij dunkt dat pipiruṣa in het Oud-Jav. Rāmāyaṇa niets anders is dan een geredupliceerde irrealis vorm van $\vee$ pirus, d.i. dus: willende of zullende als ,pirus” optreden.

\section{Het Rāmāyana.}

Tenslotte moge ik nog de aandacht vestigen op het voorkomen van de woorden ,....macarita Rāmāyaṇa”.... (II B 10). Bij al de on-

56) Aldus ongeveer, Prof. Berg in een persoonlijk onderhoud met mij.

57) Ms. Or. 4570 uit het Legatum Warnerianum, blz. 48. Men zij er aan herinnerd dat dit Ms. een verzameling van verschillende ,woordenboeken” is en o.a. ook het Amaramāla bevat. Cf. Kern, Verspr. Geschr. dl. IX, blz. 272.

58) In zịjn Kawi-Balineesch-Nederlandsch woordenboek s.v. pipirușa. 
zekerheden die de eigennamen in het laatste stuk van oorkonde II leveren - nl. of die eigennamen behooren bij personen of bij tooneelspelen en dergelijke - valt er niet te twijfelen aan de beteekenis van de hierboven aangehaalde woorden. Men droeg het Rāmāyaṇa voor. Zooals bekend is heeft R. Ng. Dr. Poerbatjaraka in een tweetal suggestieve opstellen aannemelijk trachten te maken dat de OudJavaansche Kakawin-bewerking van het Rāmāyaṇa gedateerd kan worden ,,in de buurt van Balitung's regeering” ${ }^{59}$ ). Op onze oorkonde hebben wij bij elkaar de vermelding van den mahārāja raka i Watukura (d.i., zooals wij weten, Balitung) en het Rāmāyaṇa. Wij kunnen echter geen enkele aanwijzing vinden om dit Rāmāyana te identificeeren met de ons bekende Kakawin Rāmāyaṇa.

In onze oorkonde staat „,... macarita Rāmāyaṇa”. En voor zoover wij dit kunnen nagaan wordt macarita in de Oud-Javaansche litteratuur gebruikt in de beteekenis van: voordragen van prozawerken. Het Oud-Javaansche Ādiparwa-prozawerk wordt een ,carita” genoemd ${ }^{60}$ ) en van dengene die het Wirātaparwa, dat eveneens in proza is geschreven, voordraagt wordt gezegd dat hij ,,macarita” ${ }^{61}$ ). Daarentegen verklaren de verschillende dichters van kakawins nadrukkelijk aan het begin of aan het einde van hun werken, dat zij ,,mikĕt”, ${ }^{62}$ ) d.w.z. in gebonden stijl weergeven, een of andere ,,carita”, d.i. prozastuk.

Zoo gezien is er dus meer kans, dat het Rāmāyaṇa genoemd in onze oorkonde II, n iet de ons bekende Kakawin Rāmāyaṇa is. Welk Rāmāyaṇa het dan wel is, dat voorgedragen werd in den tijd van Koning Balitung, ter opluistering van het feest, beschreven in onze oorkonde, het antwoord op deze belangrijke vraag zijn wij helaas niet in staat te geven.

Voorburg, Januari 1935.

59) In: $1^{\circ}$ : Gedenkschrift bij gelegenheid van het 75 -jarig bestaan van het Kon. Inst. voor de Taal-, Land- en Volkenkunde van Ned.-Indië, blz. 265-272 en $2^{\circ}$ T. B. G. 72 (1932), blz. 151-214: „Het Oud-Javaansche Rāmãyaṇa”. Zie aldaar blz. 161.

60) Ádiparwa ed. Dr. H. H. Juynboll, blz. 2, regel 5.

61) Wirāțaparwa ed. Dr. H. H. Juynboll, blz. 98, regel 5.

62) Of er staat in ander syntactisch verband een hieraan passende andere vorm van Vikět. Cf. b.v. Rāmāyaṇa ed. Kern XXVI 51. Arjuna wijaya en Sutasoma in de Pararaton ed. Brandes, resp. bl. 162, regel 1 van het eerste citaat en regel 1 van het derde citaat. Arjuna wiwāha ed. Poerbatjaraka I. 2 en XXXVI. 2. 